\title{
Sistem Penunjang Keputusan Pelayanan Teknis PT. PLN Dengan Metode Simple Additive Weighting
}

\author{
Mike Puji Arni ${ }^{1}$, Laura Saraswati Nusantara ${ }^{2}$, M. Roziq Zainuddin ${ }^{3}$ \\ ${ }^{1}$ masmus.sanqta@gmail.com, ${ }^{2}$ laurasalsabila@ymail.com, ${ }^{3}$ m_roziq@yahoo.co.id
}

Program Studi Teknik Informatika, Fakultas Teknologi Informasi, Universitas Merdeka Pasuruan

\begin{abstract}
Technical services is State Electricity Company (PT. PLN Persero) especially on Gondang Wetan district, Pasuruan Area in order to improve it's services to the customers. Technical services power failure could be optimal if all the customer's complaints resolved properly. Decision Support System is developed in order to manage customers data of power failure appropriately and provide an overview to the Manager and Technic Supervisor for decision making. This research use Simple Additive Weighting ( $S A W$ ) method to clasisify the type and symptomps of power failure and other variable which support the process of handling power failure. This method can help Manager to find out the power failure that often occurs to produce accurate data for reporting to the Leader of PT. PLN Pasuruan.
\end{abstract}

Intisari- Pelayanan Teknis adalah satu produk PT. PLN Persero dalam rangka peningkatan pelayananan kepada Pelanggan. Khususnya pada PT. PLN Rayon Gondang Wetan, Pasuruan, pelayanan teknis untuk gangguan berfungsi optimal apabila setiap pengaduan dan keluhan data pelanggan mampu terselesaikan dengan baik. Untuk itu dikembangkan sistem DSS (Decision Support System) agar data gangguan pelanggan dapat dikelola secara benar dan tepat, serta memberikan gambaran kepada Manager dan Supervisor Teknik guna memudahkan pengambilan keputusan. Pada penelitian ini untuk pengelompokan jenis gangguan, gejala gangguan dan variabel lain yang menunjang dalam proses penanganan gangguan digunakan Metode Simple Additive Weighting (SAW). Dengan metode ini, dengan cepat mengetahui gangguan yang sering terjadi untuk cepat ditindak lanjuti dalam proses laporan kepada Pimpinan PT. PLN APJ Pasuruan.

Kata Kunci- PT. PLN, Pelayanan Teknis, Gangguan, Decision Support System, Simple Additive Weighting

\section{PENDAHULUAN}

Listrik merupakan salah satu kebutuhan utama dalam masyarakat. Tanpa adanya listik, lampu, alat, mesin, dan teknologi yang biasa digunakan dalam kehidupan sehari-hari tidak dapat berfungsi. Sebagian besar kebutuhan energi listrik ini dapat diperoleh melalui pasokan dari Perusahaan Listrik Negara (PT. PLN) [9]. Kepuasan pelanggan harus diutamakan karena dukungan dan peran pelanggan memiliki keterkaitan nyata dengan usaha PT. PLN Rayon Gondang Wetan, Pasuruan [1]. Tidak hanya itu, kualitas pelayanan dari PT. PLN Rayon Gondang Wetan, Pasuruan sendiri tentu menjadi satu tugas dan tanggung jawab dari PT. PLN pada rayon tersebut. Kualitas listrik ini tentu sangat dirasakan oleh seluruh pelanggan setiap hari. Di kota besar misalnya, apabila terjadi pemadaman listrik, saluran yang putus, atau trafo meledak, tentu akan sangat mengganggu kegiatan masyarakat. selain itu gangguan-gangguan kecil seperti saluran listrik rumahan yang putus atau terganggu, atau pencatatan $\mathrm{kWh}$ meter yang salah, tentu saja akan menjadi komplain.

Dengan adanya pelayanan pengaduan, maka diperlukan suatu rekapitulasi pengolahan data yang lebih baik. Rekapitulasi pengolahan data merupakan keseluruhan proses pengelompokan atau pembuatan rincian data yang bercampur aduk. Rekapitulasi adalah suatu kegiatan meringkaskan data sehingga menjadi lebih berguna bentuk, susunan, sifat atau isinya dengan bantuan tenaga tangan atau bantuan suatu peralatan dan mengikuti rangkaian langkah, rumus, atau pola tertentu [8]. Untuk itulah rekapitulasi pengolahan data dengan perancangan basis data dapat menjawab semua pertanyaan yang muncul. Salah satu bentuk informasi yaitu dengan pemanfaatan sistem-sistem informasi berbas is ko mputer [4][5]. Komputerisasi merupakan suatu alternatif yang tepat untuk seorang pemakai dalam kebutuhan akan informasi secara tepat, dalam hal ini adalah bagi seorang admin dan operator telepon [9].

\section{KAJIAN PUSTAKA}

\section{A. Metode Simple Additive Weighting (SAW)}

Metode Simple Additive Weighting (SAW) sering juga dikenal istilah metode penjumlahan terbobot. Konsep dasar metode SAW adalah mencari penjumlahan terbobot dari rating kinerja pada setiap alternatif pada semua atribut [1]. Metode SAW membutuhkan proses normalisasi matriks keputusan (X) ke suatu skala yang dapat diperbandingkan dengan semua rating alternatif yang ada. Metode ini merupakan metode yang paling terkenal dan paling banyak digunakan dalam menghadapi situasi Multiple Attribute Decision Making (MADM). MADM itu sendiri merupakan suatu metode yang digunakan untuk mencari alternatif optimal dari sejumlah alternatif dengan kriteria tertentu [2][3][7].

\section{B. Formula $S A W$}

1. Menentukan kriteria - kriteria yang akan dijadikan acuan dalam pengambilan keputusan, yaitu Ci.

2. Menentukan rating kecocokan setiap alternatif pada setiap kriteria.

3. Membuat matriks keputusan berdasarkan kriteria (Ci), kemudian melakukan normalisasi matriks berdasarkan persamaan yang disesuaikan dengan jenis atribut (atribut keuntungan ataupun atribut biaya) sehingga diperoleh matriks ternormalisasi $\mathrm{R}$. 
4. Hasil akhir diperoleh dari proses perankingan yaitu penjumlahan dari perkalian matriks ternormalisasi $\mathrm{R}$ dengan vektor bobot sehingga diperoleh nilai terbesar yang dipilih sebagai alternatif terbaik (Ai) sebagai solusi.

Formula untuk melakukan normalisasi tersebut seperti pada rumus (1) berikut [2]:

$$
r_{i j}=\left\{\begin{array}{l}
\frac{x_{i j}}{\operatorname{Max}_{i} x_{i j}} j i k a j \text { adalah atribut keuntungan (benefit) } \\
\frac{\operatorname{Min}_{i} x_{i j}}{x_{i j}} \text { jika } j \text { adalah atribut biaya }(\text { cost })
\end{array}\right.
$$

Dimana :

rij = rating kinerja ternormalisasi

Maxij = nilai maksimum dari setiap baris dan kolom

Minij = nilai minimum dari setiap baris dan kolom

Xij = baris dan kolom dari matriks

Dengan rij adalah rating kinerja ternormalisasi dan alternatif Ai pada atribut $\mathrm{Cj} ; \mathrm{i}=1,2, \ldots . \mathrm{m}$ dan $\mathrm{j}=1,2, \ldots, \mathrm{n}$.

Pada rumus (2) menunjukkan rumus Preferensi Alternatif untuk setiap alternatif (Vi) diberikan sebagai berikut :

$$
V_{i}=\sum_{j=1}^{n} W_{j} r_{i j}
$$

Dimana:

$$
\begin{array}{ll}
\mathrm{Vi} & =\text { Nilai akhir dari alternatif } \\
\mathrm{wj} & =\text { Bobot yang telah ditentukan } \\
\mathrm{rij} & =\text { normalisasi matriks }
\end{array}
$$

\section{METODE PENELITIAN}

\section{A. Desain Proses}

Tahap awal pada penelitian ini adalah perancangan atau desain proses sistem yang akan dibangun. Penelitian ini menggunakan diagram alir (flowchart) dokumen dan Diagram Alir Data (Data Flow Diagram) sebagaiberikut:

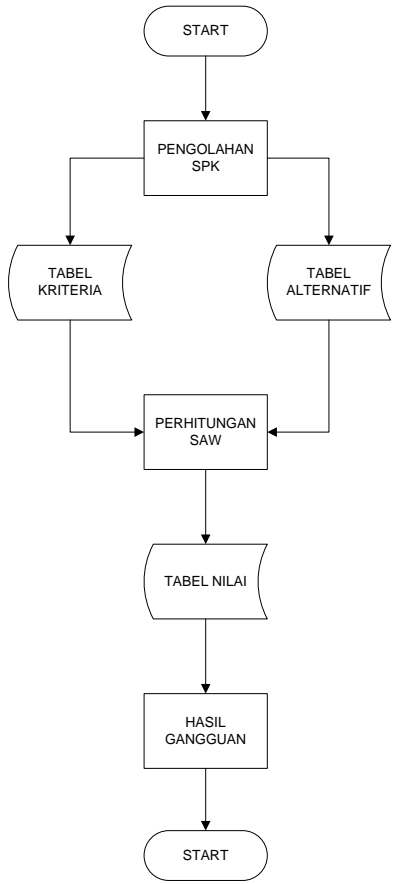

Gambar 1. Flowchart Proses Penilaian
1. Flowchart Proses Penilaian

Proses penilaian, yang menjelaskan bahwa pada pengolahan data diperlukan data yang ada pada table Alternatif dantabel Kriteria. Setelah data-data tersebut telah siap, maka dilanjutkan pada proses perhitungan dengan metode Simple Additive Weighting, yang kemudian disimpan pada table Nilai. Setelah melalui beberapa proses, dilanjutkan dengan proses yang terakhir yaitu proses Pencetakan Hasil Gangguan seperti yang ditunjukkan pada Gambar 1 .

1.1 DFD Level 0

DFD Level 0, dimana pada level ini merupakan gambaran keseluruhan aliran data yang terjadi pada keseluruhan proses. Diagram Alir Data ditunjukkan pada Gambar 2.

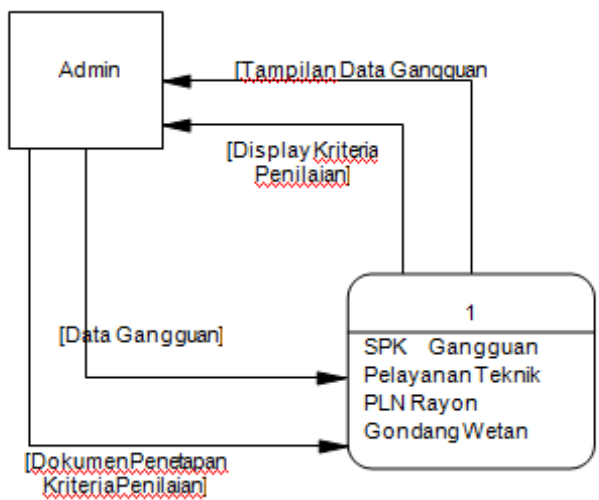

Gambar 2. DFD Level 0 SPK Gangguan

\subsection{ERD Dalam Bentuk Context Diagram}

ERD dalam bentuk CDM yang saling berhubungan dan relasi. Adapun relasi yang saling terhubung sebagaiberikut :

a) Relasi one to many antara table Alternatif dan table Nilai, artinya satu table Alternatif mempunyai beberapa penilaian.

b) Relasi one to many antara table Kriteria dan table Nilai, artinya dalam satu Kriteria terdiri dari beberapa Penilaian

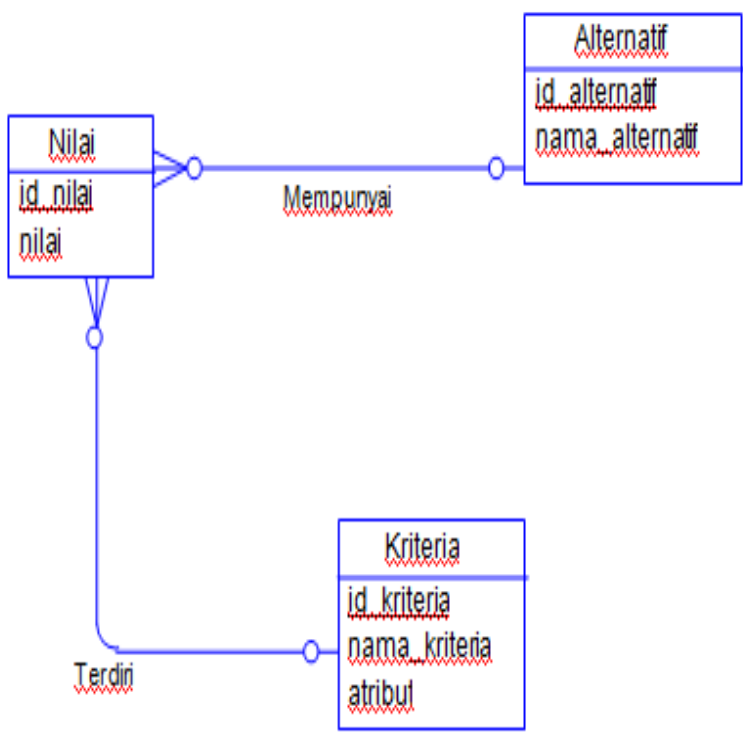

Gambar 3. ERD dalam bentuk CDM 


\section{HASIL DAN PEMBAHASAN}

\section{A. Tampilan Home}

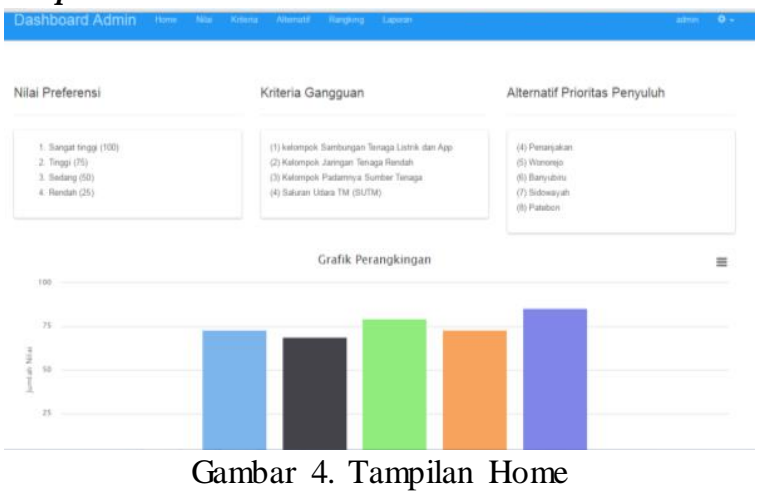

Pada tampilan Home gambar 4 berisikan Nilai Preferensi, Kriteria Gangguan, Alternatif Prioritas Penyulang dan Grafik Perangkingan.

\section{B. Tampilan Data Nilai Preferensi}

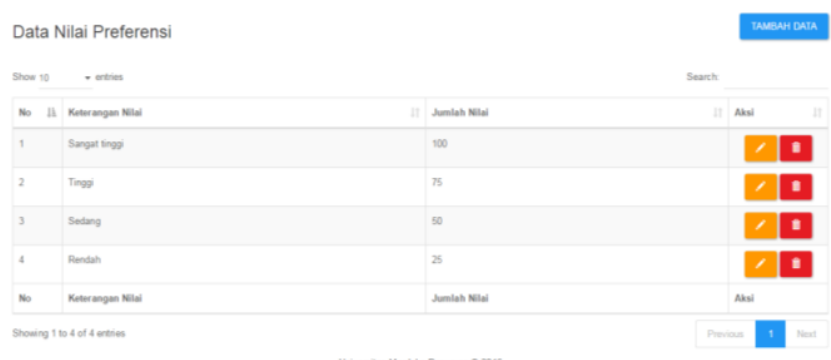

Gambar 5. Tampilan Data Nilai Preferensi

Pada gambar 5 view data nilai preferensi terdapat pilihan edit dan hapus. Jika terdapat kesalahan dalam memasukan data bisa mengubahnya dengan mengklik to mbol edit, maka tampilah halaman koreksi data nilai preferensi dan kemudian mengklik tombol simpan.

\section{Tampilan Data Kriteria}

Pada gambar 6 Input data kriteria dimaksudkan bisa memasukkan penginputan data kriteria jenis gangguan. Pada tampilan ini menampilkan Nama Kriteria, Tipe Kriteria dan Nilai Kriteria

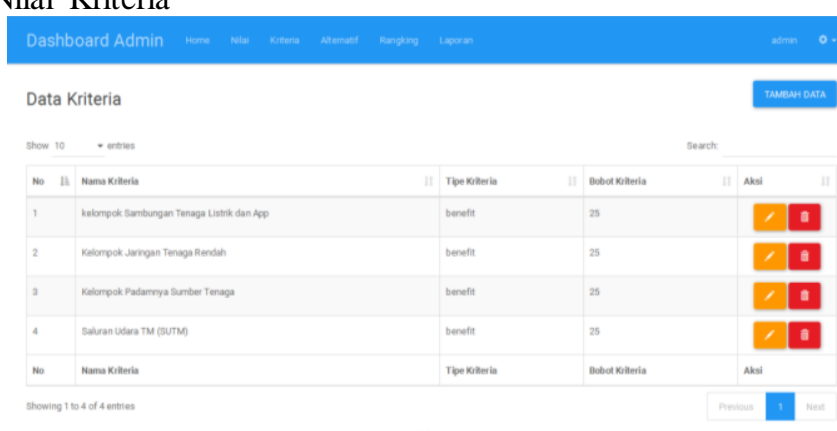

Gambar 6 Tampilan Data Kriteria

\section{Tampilan Data AlternatifPenyulang}

Pada gambar 7 tampilan Data Alternatif Penyulang dije laskan isi Nama Penyulang dan Nilai Hasil Alternatif dari proses perhitungan metode Simple Additive Weighting.

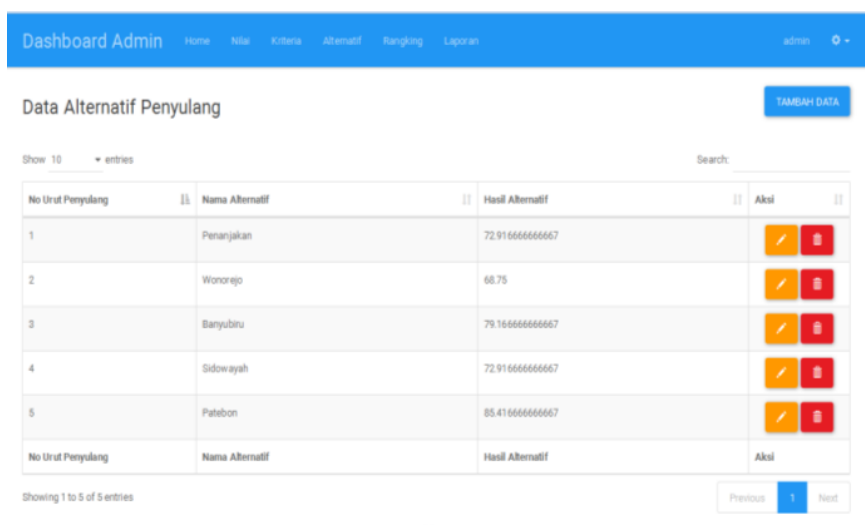

Gambar 7. Tampilan Data Alternatif Penyulang

\section{E. Tampilan Data Rangking}

Pada gambar 8 menampilkan jenis Alternatif, macammacam kriteria dan nilai dari masing-masing kriteria.

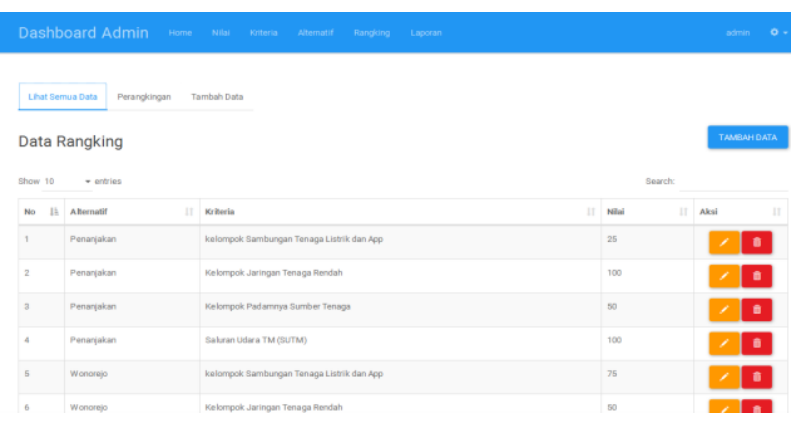

Gambar 8 Tampilan Data Rangking

\section{F. Tampilan Normalisasai R Perangkingan}

Pada gambar 9 menampilkan hasil perh itungan normalisasi $\mathrm{R}$ perangkingan dari masing-masing kriteria gangguan

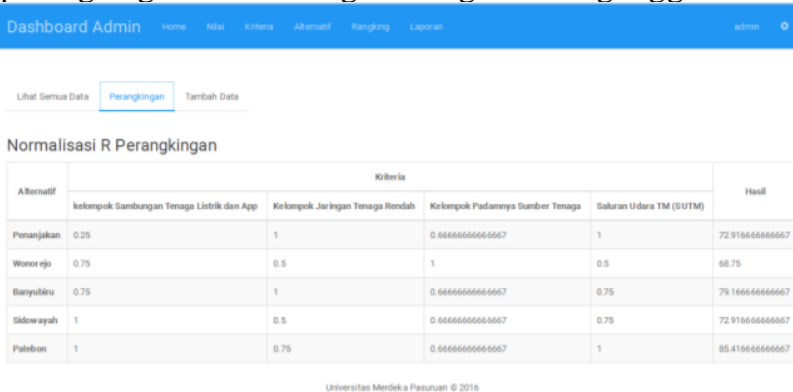

Gambar 9 Tampilan Normalisasi R Perangkingan

\section{G. Tampilan Laporan dalam Bentuk PDF}

Pada gambar 10 menampilkan cetak laporan Nilai Alternatif Kriteria dalam bentuk PDF 


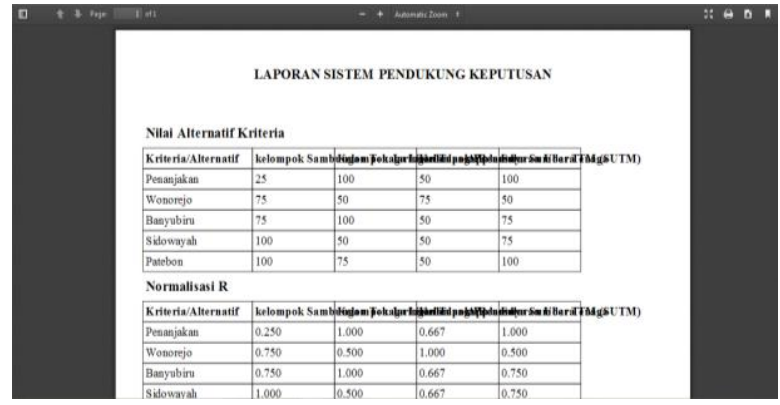

Gambar 10 Tampilan Laporan dalam Bentuk PDF

\section{H. Tampilan Laporan dalam Bentuk Table Export}

Pada gambar 14 menampilkan cetak laporan Nilai Alternatif Kriteria dalam bentuk Table Export.

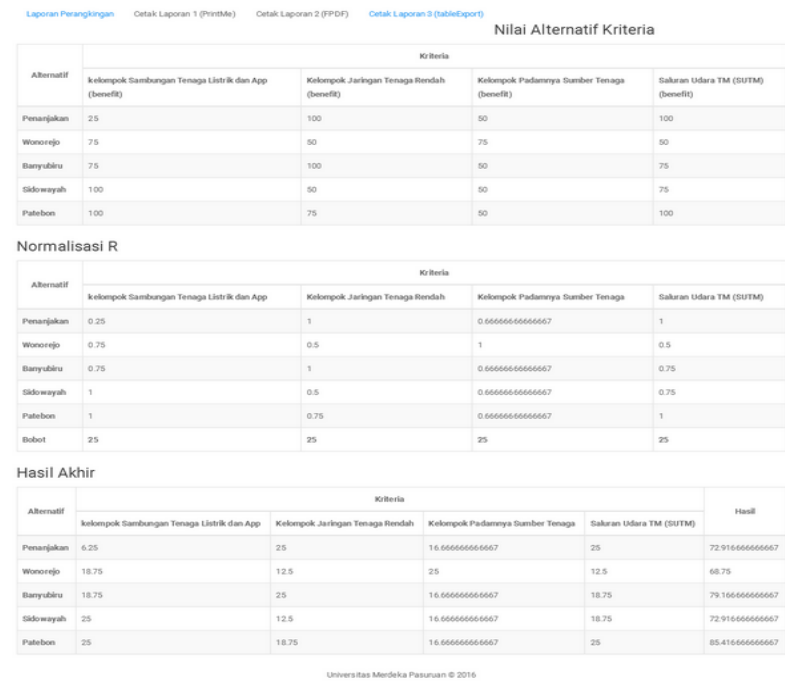

Gambar 11 Tampilan Laporan dalam Bentuk Table Export

\section{KESIMPULAN DAN SARAN}

Dengan adanya sistem ini, permasalahan yang ada di kantor PLN Rayon Gondang Wetan bisa terintegrasi. Dengan Sistem Pengambilan Keputusan pengelompokan data dan informasi yang dihasilkan lebih cepat secara komputerisasi. Aplikasi Pengambilan Keputusan tentang Pelayanan Teknik Gangguan akan mempercepat atau mengefisiensikan pekerjaan pengolahan data tersebut secara online.

Metode Simple Additive Weighting dalam Pelayanan Teknik Gangguan akan lebih cepat merekomendasikan gangguan disetiap Penyulang yang ada di wilayah jaringan Rayon Gondang Wetan.

Saran yang diberikan penulis dalam penelitian ini Dengan sistem yang sudah ada agar dapat dilakukan penambahan sub kriteria yang lebih banyak. Sistem Pengambilan Keputusan metode Simple Additive Weighting lebih menguntungkan dibandingkan dengan metode yang lain sehingga dapat diketahui tingkat akurasinya.

\section{Ucapan Terima Kasih}

Penulis mengucapkan terima kasih kepada Bapak Rudi Hariyanto, S.Kom dan Bapak Anang Aris Widodo S.Kom yang telah membimbing untuk pembuatan jurnal ini.

\section{DAFTAR PUSTAKA}

[1] Budi Artono, M. Aziz Muslim, dan Onny Setyawati. "Sistem Pengambilan Keputusan Menggunakan Metode Group Technology untuk Pelayanan Teknis PT. PLN Rayon Ngunut".Jumal EECCIS Vol. 8, No. 2, Desember 2014. (diakses pada tanggal 03/06/2016 pada jam 09.32 WIB)

[2] Fishburn, 2006, Metode Simple Additive Weighting, (Dikutip: Kusumadewi).

[3] Kusrini. 2007, Konsep dan Aplikasi Sistem Penunjang Keputusan, Yogyakarta : Andi Offset.

[4] Hikmah, Agung Baitul., Supriadi, Deddy., Alawiyah, Tuti. 2015. Cara Cepat Membangun Website dari Nol. Yogyakarta: ANDI hal. 1-2 (Pengertian Website dan dreamweaver)

[5] Sugianto, Mikael. 2007. Microsoft Visio 2007 Membuat Beragam Desain Diagram dan Flowchart. Jakarta : Salemba Infotek

[6] https://books.google.co.id (diakses pada tanggal 20/05/2016 pada jam 08.00 WIB)

[7] https://id.wikipedia.org/wiki/Sistem Pendukung Keputu $\underline{\text { san }}$ (diakses pada tanggal 14/04/12016 pada jam 10.16 WIB)

[8] kbbi.web.id/rekapitulasi (diakses pada tanggal 21/3/2016 pada jam 10.36 WIB)

[9] www.pln.co.id (diakses pada tanggal 24/06/2016 pada jam 12.24 WIB) 